\title{
Michał Lubina
}

Jagiellonian University (Poland)

ORCID: 0000-0002-3342-1763

e-mail: michallubina@wp.pl

\section{Beyond "Academic Diplomacy"}

\author{
Book Review: Chosein Yamahata, Sueo Sudo, Takashi Matsugi (Eds.), Rights and \\ Security in India, Myanmar, and Thailand, Singapore 2020.
}

Edited volumes are by definition difficult to make and even more difficult to assess fairly. Editors face the challenging task of accepting articles that fit in with the volume's concept while rejecting those that do not. The result is rarely black and white. More often, some articles are good while others are less so (or the other way round: a couple of good articles save an otherwise unsuccessful volume). The task gets even more challenging when the edited volume is thought to be based on a specific theoretical and methodological line. It was precisely the case with recently published Rights and Security in India, Myanmar, and Thailand edited by Japanese researchers Chosein Yamahata, Sueo Sudo, and Takashi Matsugi.

The overarching concept of this book is the idea of "academic diplomacy". As the editors write, by introducing this idea, they hope to integrate non-academic means (such as indigenous knowledge) into academia and to reach out with academic knowledge and sensibility to the outside world (to go out of the iron towers). In other words, it is academic diplomacy or diplomacy of academia that hopes to offer a different, non-political solution to the world's dire problems and challenges, such as hunger, inequality, and injustice of all kinds. At its core is what is called "preventive diplomacy": a soft intervention built on a notion that community is an empowered agent that can make a difference: it can improve societies. Simply put, politicians, diplomats, scholars, civil society activists, media people, independent citizens, and others can play a constructive role in making this place a better place to live. They can offer peaceful means to solving critical, global problems. 
It all sounds benevolent, but what exactly this "academic diplomacy" is, remains less clear. It is described by a fair amount of sophisticated vocabulary and detailed charts, but after reading the book, it leaves the reviewer with an impression that the idea seems a bit vague and needs to be conceptualized more comprehensively. It is still on its way to becoming a well-thought-out theory. Intriguingly, the "academic diplomacy" concept is not used as a consequential theoretical line in this volume. Out of 12 articles in this volume, only two mention "academic diplomacy": the first one (an introduction to the book) and the last one (about Myanmar's transition case study). We may add article no. 3 (about urban poverty in India) to the list as it refers to it indirectly. But that is all. It is still only 3 out of 12 . The rest does not use it, either explicitly or less so.

Eclecticism is the first word that comes to mind when assessing this edited volume. It effectively covers four countries: India and two Southeast Asian (Myanmar and Thailand) plus Japan's policy towards the region. Topics vary from geopolitics via political parody in post-coup Thailand to women organizations among Myanmar's ethnic minorities. The level of this volume is uneven, too: it is a fascinating mix of significant inputs with less so. Some of the articles are pretty hermetic - they require a coffee or two to read it - while others are superb pieces that make it a well-worth read.

Takashi Tsukamoto's "Escalation of Ethno-Cultural Tensions in Southern Thailand in the Midst of Assimilation and Homogenization" is the best one. Based on primary sources from Thai archives, this seminal piece presents the Thai nation-building in the South of Thailand (former Patani). It shows the side effects of post-1932 Thai nation-building: how local Muslims went the way from unproblematic outsiders into discordantly perceived un-Thai elements in the society. In other words, it shows how they became un-Thai or the national Other. Aside from this theme, the Takashi offers no small amount of secondary, yet fascinating still issues, such as post-war identity political compromise (Patani's people were allowed to identify themselves as Muslims but not as Malays) or WWII maneuverings (Patani's hopes for independence, informally enhanced by Great Britain). In short, this article is a must-read.

Donald Seekins' piece “The Rakhine (Arakan) Buddhists: A Little Known Minority in Myanmar" on the Arakanese people in Myanmar (who have - as Seekins brilliantly compared - an image of a "Southeast Asian Ku Klux Klan" in the West) is good and interesting, too, even if much of it is a repetition of Author's previous texts. David M. Potter's "Japanese Development Assistance, Geopolitics, and 'Connectivity' in the Mekong Region: Implications for Aid to Myanmar" is gripping as it offers non-obvious observations (the Burmanocentricism of Japanese aid to Myanmar) and discloses Japanese strategic goals behind aid to Myanmar quite well. Paul Chambers' piece on military power in Thailand is excellent and well written, too (e.g., examples of parallel states "include the Sicilian mafia, Afghanistan warlords, the Rwandan Hutu tribe, and the Thai monarchy.") Aside from presenting the convincing concept of a "parallel state", its principal value is in showing that within the political Siamese twins (monarchy and military) it is the monarchy that has the 
upper hand. Finally, the concluding article by Chosein Yamahata, an expert on Myanmar, is an excellent mix of intriguing theoretical observations (Collier-Hoeffler's model of the dual causes of conflict in the Global South: either "greed" or "grievance"), thought-provoking historical comparisons (2008 constitution like the British colonial Dyarchy) and fascinating predictions (from quite fantastic ones, like Chinese intervention, to more probable, like climate inflicted ones). There are some other decent articles in the volume. Sueo Sudo's “Japan's Mekong Policy and Myanmar: Complementing a Viable Strategic Partnership," Khen Suan Khai's "De facto State Religion as a Threat to Freedom of Religion and Belief: Case Study of Ethnic Chin Christians in Burma/Myanmar" or Souvanic Roy's "Development Efforts towards Ecological Sustainability in Calcutta: Transformation of a Metropolis," are also worth a read.

Thus, as one can see from this list, there are eight valuable articles (out of 12). And for their sake, it is well-worth to read this edited volume and turn a blind eye to some of its shortcomings. 
